\title{
The prognostic significance of nuclear expression of PHF2 and C/EBPa in clear cell renal cell carcinoma with consideration of adipogenic metabolic evolution
}

\author{
Jeong Hwan Park ${ }^{1,2}$, Minsun Jung ${ }^{1}$ and Kyung Chul Moon ${ }^{1,3}$ \\ ${ }^{1}$ Department of Pathology, Seoul National University College of Medicine, Seoul, Republic of Korea \\ 2 Department of Pathology, SMG-SNU Boramae Medical Center, Seoul, Republic of Korea \\ ${ }^{3}$ Kidney Research Institute, Medical Research Center, Seoul National University College of Medicine, Seoul, Republic of Korea \\ Correspondence to: Kyung Chul Moon, email: blue7270@snu.ac.kr \\ Keywords: PHF2, C/EBPa, clear cell renal cell carcinoma, adipogenesis, progression \\ Received: May 12, $2017 \quad$ Accepted: July 25, $2017 \quad$ Published: August 04, 2017
}

Copyright: Park et al. This is an open-access article distributed under the terms of the Creative Commons Attribution License 3.0 (CC BY 3.0), which permits unrestricted use, distribution, and reproduction in any medium, provided the original author and source are credited.

\section{ABSTRACT}

Clear cell renal cell carcinoma (CCRCC) is the most common subtype of renal cell carcinoma (RCC), and it has an unfavourable prognosis compared to other RCCs. Plant homeodomain finger 2 (PHF2) and CCATT/enhancer binding protein a (C/EBPa) play a role in the epigenetic regulation of adipogenesis, and their tumour suppressive functions have been elucidated. This study aimed to assess the nuclear expression of PHF2 and C/EBPa in CCRCC and to evaluate their role in pathogenesis and prognosis. The nuclear expression of PHF2 and C/EBPa was evaluated in 344 cases of ccRCC by immunohistochemistry, and adipogenesis was assessed based on cytoplasmic features. Low expression was significantly associated with a larger tumour size, higher WHO/ISUP grade, high pT, pM, and advanced pTNM stage. Additionally, the expression level was correlated with the cytoplasmic features of cCRCC. The low expression group had significantly shorter cancer-specific and progression-free survival times. Furthermore, multivariate analysis showed that the combination of PHF2 and C/EBPa expression as an independent prognostic factor for cancer-specific and progressionfree survival. In conclusion, our results suggest that nuclear expression of PHF2 and C/EBPa may serve as a prognostic marker and that the oncogenic metabolic shift has progressed in CCRCC patients.

\section{INTRODUCTION}

Renal cell carcinoma (RCC) is the most common cancer of the kidney and is amongst the most lethal urinary malignancies [1]. Patients with RCC presented with metastatic disease at rates of $30 \%$ and higher, and approximately $40 \%$ had local recurrence or distant metastases develop during follow-up [2, 3]. Among various subtypes of RCC, clear cell RCC (ccRCC) is the most common histologic subtype, accounting for 65 to $70 \%$ of all renal malignancies, and it has a less favourable prognosis than other RCC subtypes [4]. ccRCC metastasis mainly occurs via haematogenous spread, and the lungs, bone, and liver (in order) are common metastatic sites [5]. The outcome of metastatic RCC is dismal, and the 5-year survival of metastatic RCC is estimated to be less than
$10 \%[6]$.

The molecular characteristics of ccRCC have been elucidated with the development of molecular studies including the next-generation sequencing (NGS) technique $[4,7,8]$. In considering the genetic alteration levels, mutations in the Von Hippel-Lindau (VHL) gene, which acts as tumour suppressor gene by stabilizing hypoxia inducible factors (HIF-1 $\alpha$ and HIF- $2 \alpha$ ) and the polybromo-1 (PBRM1) gene, which are associated with chromatin remodelling are the most common alterations in ccRCC. Additionally, widespread DNA hypomethylation and metabolic shifts were identified. Based on comprehensive molecular studies, oncogenic metabolic shifts and epigenetic alterations have been considered the major pathogenic components of ccRCC.

The association of adipogenesis with ccRCC 
pathogenesis has been studied $[9,10]$. ccRCC has a typical golden yellow cut surface on gross examination and consists of tumour cells with a clear to eosinophilic cytoplasm on histology [4]. These findings are due to the cellular accumulation of lipids and glycogen. Previous studies emphasized adipose differentiation-related protein (ADFP) and revealed that the adipogenesis pathway or adipogenic differentiation is associated with tumourigenesis and the prognosis of ccRCC $[9,10]$.

Plant homeodomain finger 2 (PHF2), in concert with CCATT/enhancer binding protein $\alpha(\mathrm{C} / \mathrm{EBP} \alpha)$, plays a role in epigenetic regulation of adipogenesis [11-13]. These molecules induce transcription of genes related to adipogenesis by demethylating dimethylated histone H3 lysine 9 (H3K9me2). Alterations in PHF2 have been identified in several cancer types, including breast, oesophageal, stomach and colon cancer [1416]. Additionally, $\mathrm{C} / \mathrm{EBP} \alpha$ has a role in tumourigenesis in various cancers, including acute myeloid leukaemia (AML) and cancers of the lungs, liver, breast, skin and ovaries [17-19]. Furthermore, both PHF2 and C/EBP $\alpha$ interact with $\mathrm{p} 53$ and act as tumour suppressors $[16,20]$. However, the adipogenic role and association with the prognosis of ccRCC for PHF2 and C/EBP $\alpha$ have not yet been studied.

In this study, we postulated that the adipogenesis pathway with PHF2 and $\mathrm{C} / \mathrm{EBP} \alpha$ is associated with pathogenesis and prognosis of ccRCC. We evaluated adipogenesis by assessing the cytoplasmic features of ccRCC samples. Additionally, we assessed the nuclear expression of PHF2 and $\mathrm{C} / \mathrm{EBP} \alpha$ in ccRCC samples using immunohistochemistry. Additionally, we assessed the clinicopathological correlation with PHF2 and C/ EBP $\alpha$ expression and evaluated the prognostic value. Furthermore, we proposed putative progression model of ccRCC based on our results.

\section{RESULTS}

\section{Clinical and pathological characteristics of ccRCC patients}

A total of 344 patients who underwent surgical resection and had confirmed ccRCC were analysed in this study. The patients included 251 men and 93 women. The mean age was 57 years old (range 20-80), and the average tumour size was $4.6 \mathrm{~cm}$ (range 0.5-20.0). Lymph node metastasis was found in 12 cases (3.5\%), and distant metastasis was identified in 37 cases $(10.8 \%)$. Of the 344 patients, 253 were categorized as stage I ( $73.5 \%), 28$ stage II (8.1\%), 24 stage III (7.0\%) and 39 stage IV (11.3\%). The WHO/ISUP grading scale revealed that 2 of the cases were grade $1(0.6 \%), 169$ cases were grade $2(49.1 \%), 142$ cases were grade $3(41.3 \%)$ and 31 cases were grade $4(9.0 \%)$.
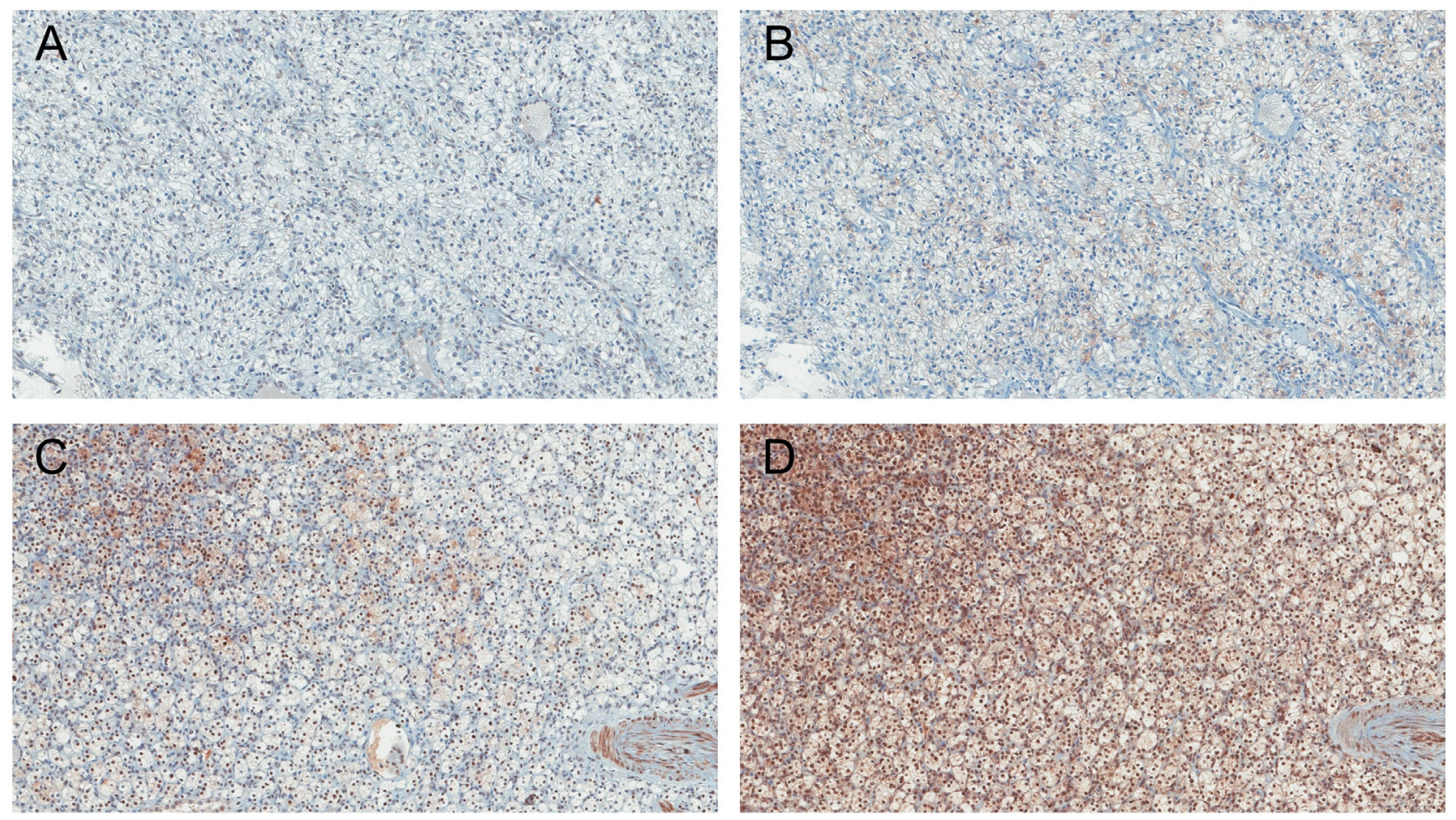

Figure 1: Immunohistochemical findings showing low A., B. and high C., D. nuclear expression of PHF2 and C/EBPa in ccRCC (A., C. PHF2 and B., D. C/EBP $\alpha$ ). Original magnification, $\times 100$. 
Table 1: Clinicopathologic features of patients with ccRCC and correlation between nuclear PHF2 and C/EBPa expression and clinicopathologic parameters.

\begin{tabular}{|c|c|c|c|}
\hline & \multicolumn{2}{|c|}{ Nuclear expression of PHF2 and C/EBPa } & \\
\hline & $\begin{array}{c}\text { Low } \\
(\mathrm{n}=187)\end{array}$ & $\begin{array}{c}\text { High } \\
(\mathrm{n}=157)\end{array}$ & \\
\hline & $\mathrm{N}(\%)$ & $\mathrm{N}(\%)$ & $P$ value \\
\hline Age (years) & & & 0.083 \\
\hline$\leq 57 \mathrm{yrs}$ & $82(43.9)$ & $84(53.5)$ & \\
\hline$>57 \mathrm{yrs}$ & $105(56.1)$ & $73(46.5)$ & \\
\hline Gender & & & 0.396 \\
\hline Female & $47(25.1)$ & $46(29.3)$ & \\
\hline Male & $140(74.9)$ & $111(70.7)$ & \\
\hline Tumour size $(\mathrm{cm})$ & & & $<0.001$ \\
\hline$\leq 7 \mathrm{~cm}$ & $139(74.3)$ & $140(89.2)$ & \\
\hline$>7 \mathrm{~cm}$ & $48(25.7)$ & $17(10.8)$ & \\
\hline WHO/ISUP grade & & & 0.003 \\
\hline Grade $1 / 2$ & $79(42.2)$ & $92(58.6)$ & \\
\hline Grade 3 / 4 & $108(57.8)$ & $65(41.4)$ & \\
\hline T stage & & & 0.003 \\
\hline $\mathrm{T} 1$ & $131(70.1)$ & $132(84.1)$ & \\
\hline T 2 & $32(17.1)$ & $9(5.7)$ & \\
\hline T 3 & $18(9.6)$ & $15(9.6)$ & \\
\hline T 4 & $6(3.2)$ & $1(0.6)$ & \\
\hline $\mathrm{N}$ stage & & & 0.073 \\
\hline $\mathrm{N} 0 / \mathrm{Nx}$ & $177(94.7)$ & $155(98.7)$ & \\
\hline N1 & $10(5.3)$ & $2(1.3)$ & \\
\hline M stage & & & 0.003 \\
\hline M0 & $158(84.5)$ & $149(94.9)$ & \\
\hline M1 & $29(15.5)$ & $8(5.1)$ & \\
\hline Stage & & & 0.003 \\
\hline $\mathrm{I}$ & $124(66.3)$ & $129(82.2)$ & \\
\hline II & $20(10.7)$ & $8(5.1)$ & \\
\hline III & $13(7.0)$ & $11(7.0)$ & \\
\hline IV & $30(16.0)$ & $9(5.7)$ & \\
\hline Cytoplasm & & & $<0.001$ \\
\hline clear & $92(49.2)$ & $108(68.8)$ & \\
\hline eosinophilic & $73(39.0)$ & $47(29.9)$ & \\
\hline high grade & $22(11.8)$ & $2(1.3)$ & \\
\hline
\end{tabular}

During follow-up, disease progression was found in 60 cases $(17.4 \%)$ and cancer-related death was identified in 43 cases $(12.5 \%)$. The mean follow-up period was 71.8 months (from 1 to 127 months, median 76.5 months).

\section{Nuclear expression level of PHF2 and C/EBP $\alpha$ in ccRCC}

The nuclear expression level of PHF2 and $\mathrm{C} / \mathrm{EBP} \alpha$ in tumour cells was evaluated (Figure 1), and 187 (54.4\%) were classified as low expression and 157 (45.6\%) were high expression. The PHF2 and $\mathrm{C} / \mathrm{EBP} \alpha$ expression were correlated $(P<0.001$, Supplementary Table 1). Also, correlation between each protein and WHO/ISUP grade,
pTNM stage and cytoplasmic feature was identified (Supplementary Table 2). In non-neoplastic kidney tissues, we identified moderate to strong immunoreactivity of PHF2 as cytoplasmic or nuclear staining and moderate immunoreactivity of $\mathrm{C} / \mathrm{EBP} \alpha$ as cytoplasmic staining on tubular epithelial cells.

\section{Cytoplasmic features of ccRCC and correlation with PHF2 and C/EBPa expression}

The cytoplasmic features of ccRCC based on adipogenesis revealed that 200 cases had a clear cytoplasm $(58.1 \%), 119$ cases had an eosinophilic cytoplasm $(34.6 \%)$ and 25 cases had high grade features (7.3\%). 
Table 2: Multivariate analysis of cancer-specific and progression-free survival with PHF2 and C/EBP $\mathrm{Puclear}$ expression in 344 patients with ceRCC (Cox proportional hazard model).

\begin{tabular}{|c|c|c|c|c|}
\hline \multirow[b]{2}{*}{ Prognostic factors } & \multicolumn{2}{|c|}{ Cancer-specific survival } & \multicolumn{2}{|c|}{ Progression-free survival } \\
\hline & $\begin{array}{l}\text { Hazard ratio } \\
(95 \% \mathrm{CI})\end{array}$ & $P$ Value & $\begin{array}{l}\text { Hazard ratio } \\
(95 \% \mathrm{CI})\end{array}$ & $P$ Value \\
\hline WHO/ISUP grade & & 0.002 & & $<0.001$ \\
\hline 3,4 versus 1,2 & $\begin{array}{c}6.752 \\
(2.059-22.135)\end{array}$ & & $\begin{array}{c}4.332 \\
(2.011-9.330)\end{array}$ & \\
\hline pTNM stage & & $<0.001$ & & $<0.001$ \\
\hline III, IV versus I, II & $\begin{array}{c}21.500 \\
(9.844-46.956)\end{array}$ & & $\begin{array}{c}12.223 \\
(6.918-21.597)\end{array}$ & \\
\hline $\begin{array}{l}\text { PHF2 and } \mathrm{C} / \mathrm{EBP} \alpha \\
\text { nuclear expression }\end{array}$ & & 0.011 & & 0.002 \\
\hline Low versus High & $\begin{array}{c}2.491 \\
(1.228-5.052)\end{array}$ & & $\begin{array}{c}2.596 \\
(1.419-4.747)\end{array}$ & \\
\hline
\end{tabular}

CI, Confidence interval.

Low expression of PHF2 and $\mathrm{C} / \mathrm{EBP} \alpha$ was significantly associated with higher cytoplasmic features (Table 1).

\section{Correlation of PHF2 and C/EBP $\alpha$ expression with clinicopathological parameters}

The correlations of the nuclear expression of PHF2 and $\mathrm{C} / \mathrm{EBP} \alpha$ with clinicopathological parameters are shown in Table 1. Low expression was significantly associated with a larger tumour size, higher WHO/ ISUP grade, high pM stage and advanced pTNM stage. Additionally, ccRCC with low expression had a marginally significant correlation with lymph node metastasis.

\section{Association of PHF2 and C/EBP $\alpha$ expression with prognosis}

The PHF2 and C/EBP $\alpha$ expression levels had a significant correlation with the overall, cancer-specific and progression-free survival (Figure 2). The low expression group had significantly shorter overall, cancer-specific and progression-free survival periods than the high expression group. Furthermore, multivariate analysis using the Cox proportional hazards model indicated that the PHF2 and $\mathrm{C} / \mathrm{EBP} \alpha$ expression levels were an independent predictor of cancer-specific and progression-free survival in patients with ccRCC when assessed by the WHO/ISUP grade and pTNM stage (Table 2).

\section{DISCUSSION}

The association of adipogenesis with the ccRCC pathogenesis, clinicopathologic correlation and prognosis was investigated $[9,10]$. One study examined the gene expression profiles of RCCs and demonstrated that $A D F P$ gene was up-regulated in ccRCC compared to other RCC types and the normal kidney [9]. Additionally, realtime quantitative PCR revealed increased $A D F P$ mRNA levels and immunohistochemistry for ADFP showed
A

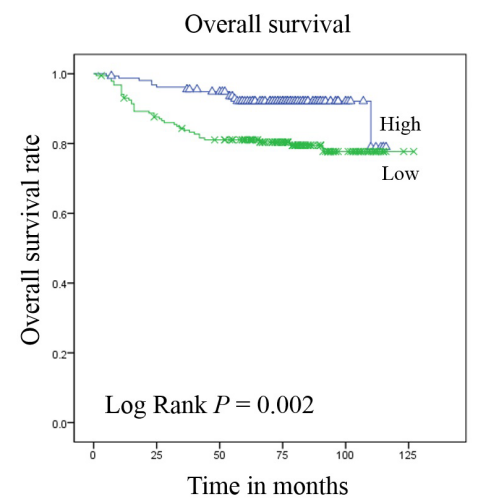

B

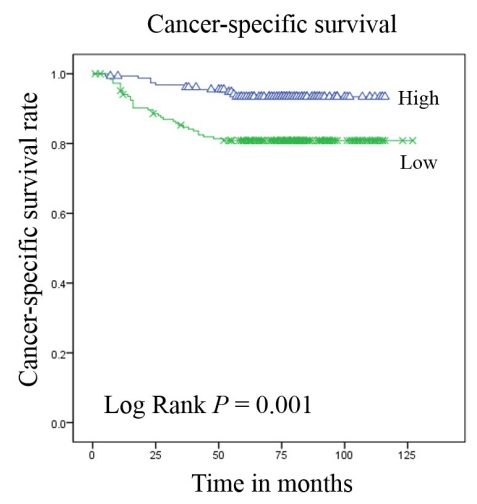

C

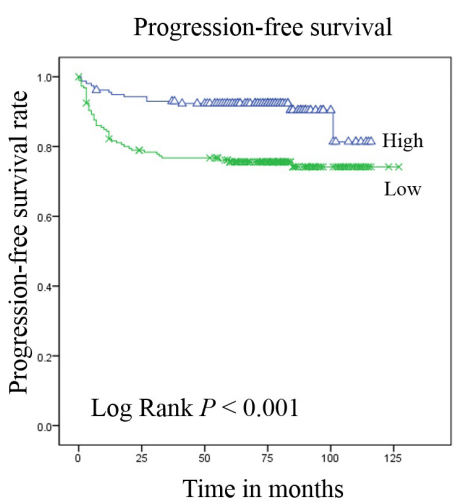

Figure 2: Kaplan-Meier curves of overall A., cancer-specific B. and progression-free C. survival in 344 patients with ccRCC according to the 2-tiered classification of PHF2 and C/EBP $\alpha$ nuclear expression. 
strong positivity in ccRCC. Moreover, a study revealed that strong $A D F P$ immunohistochemical staining was associated with a low grade and low stage in ccRCC. The $A D F P$ mRNA expression was higher in low grade than in high grade ccRCC. Univariate analysis showed that high $A D F P$ expression was related to a better prognosis for cancer-specific survival, and high $A D F P$ expression was identified as an independent prognostic factor of a better outcome by multivariate analysis. Another study revealed that ccRCC showed an adipogenic gene expression signature with $A D F P$ gene up-regulation [10]. Additionally, an immunohistochemical study revealed increased ADFP expression and a differentiation experiment on ccRCC cell lines showed adipogenic transdifferentiation in adipogenic media. A study on early-stage ccRCC showed strong ADFP staining, which is consistent with a previous study that strong staining was associated the low stage [9]. These findings and a previous study [21] encouraged us to investigate the pathogenic role and clinicopathologic correlation between adipogenesis and ccRCC.

The epigenetic regulation of adipogenesis via histone modification has been elucidated [11-13]. Histones can be modified through various reactions, including ubiquitination, glycosylation, acetylation, phosphorylation and methylation [12]. Among various modifications, acetylation and methylation play a pivotal role in adipogenic differentiation. Additionally, the specific site of lysine $(\mathrm{K})$ methylation affects the gene expression. For instance, methylation at $\mathrm{H} 3 \mathrm{~K} 9$ is associated with transcriptional silencing, whereas methylation at $\mathrm{H} 3 \mathrm{~K} 4$ is related to transcriptional activation. Recent studies have reported that PHF2, a JmjC family histone demethylase, has a role in metabolism, including adipogenesis [1113]. Studies with Phf2 knockout mice and PHF2 knockdown murine cell lines revealed that PHF2 is necessary for adipogenesis and PHF2 interacts with $\mathrm{C} / \mathrm{EBP} \alpha$ to demethylate $\mathrm{H} 3 \mathrm{~K} 9 \mathrm{me} 2[11,13]$. These results suggested that PHF2, a histone demethylase, interacts with $\mathrm{C} / \mathrm{EBP} \alpha$ and regulates the expression of genes associated with adipogenesis by demethylating $\mathrm{H} 3 \mathrm{~K} 9 \mathrm{me} 2$.

Furthermore, both PHF2 and $\mathrm{C} / \mathrm{EBP} \alpha$ have been identified to have tumour suppressive roles and interactions with p53 [14, 16-18, 22-24]. In breast cancer, alterations in
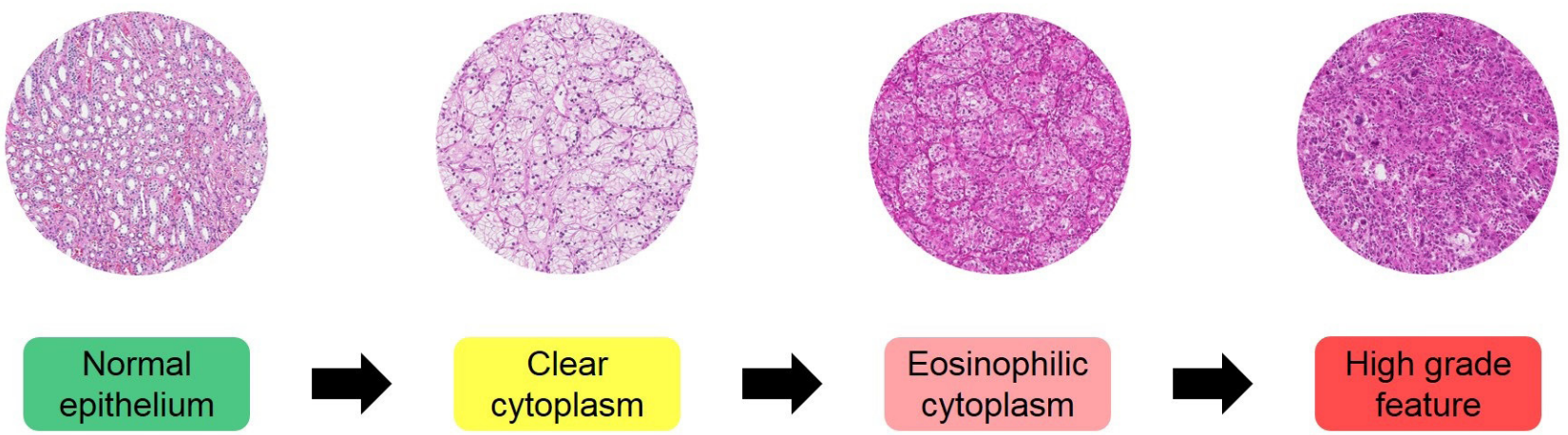

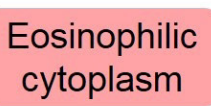

\section{High grade feature}

\author{
Oncogenic metabolic shift \\ Adipogenic differentiation \\ ADFP \\ PHF2-C/EBPa
}

Oncogenic metabolic progression

Glutamine-dependent lipogenesis

Figure 3: Proposed adipogenic metabolic evolution in ccRCC progression. 
the PHF 2 gene were observed in up to $60 \%$ of patients and reduction in the $P H F 2$ mRNA expression was identified [14]. Additionally, $P H F 2$ deletion or methylation showed a poor prognosis in the patient group $>40$ years of age. For colon cancer, PHF2 expression was decreased in cancer tissue and the Oncomine database revealed PHF2 downregulation in colon and stomach cancers [16]. Moreover, a colon and stomach cancer tissue study showed that PHF2 is positively correlated with p21 expression. In a study on HCT116 cancer cells, the authors showed that PHF2 is essential for p53 signalling pathway activation and demethylates $\mathrm{H} 3 \mathrm{~K} 9 \mathrm{me} 2$ at p53 target promoters. Based on these findings, the authors suggested that PHF2 regulates p53-target gene expression by demethylating methylated $\mathrm{H} 3 \mathrm{~K} 9$ and showed that PHF2 acts as a tumour suppressor. The association between $\mathrm{C} / \mathrm{EBP} \alpha$ and cancer has been well documented in AML $[17,18]$. C/EBP $\alpha$ is important for myeloid differentiation, and dysregulation of its expression is observed in AML and other haematolymphoid malignancies. In the lung, $\mathrm{C} / \mathrm{EBP} \alpha \mathrm{mRNA}$ expression is down-regulated in lung cancer cell lines and low expression of $\mathrm{C} / \mathrm{EBP} \alpha$ has been identified in lung cancer patients by immunohistochemistry [22]. In a breast cancer study, low expression levels of $\mathrm{C} / \mathrm{EBP} \alpha \mathrm{mRNA}$ and protein were identified, and induction of $\mathrm{C} / \mathrm{EBP} \alpha$ inhibited growth [23]. In murine squamous cell carcinoma of the skin, the $\mathrm{C} / \mathrm{EBP} \alpha \mathrm{mRNA}$ and protein expression levels were decreased in cancer cell lines. Additionally, reexpression of $\mathrm{C} / \mathrm{EBP} \alpha$ inhibited cancer cell proliferation [24]. $\mathrm{C} / \mathrm{EBP} \alpha$ is thought to act as a tumour suppressor, which interacts with various molecules, including p21, CDK2, CDK4, E2F, SWI/SNF chromatin-remodelling complex, and p53 [18, 20, 25, 26]. These study results encouraged us to evaluate the adipogenic role and association with ccRCC progression of PHF2 and $\mathrm{C}$ / EBP $\alpha$.
In this study, we assessed adipogenesis by evaluating the cytoplasmic features of ccRCC. For a precise study based on the $\mathrm{PHF} 2$ and $\mathrm{C} / \mathrm{EBP} \alpha$ function, evaluation of the methylation $\mathrm{H} 3 \mathrm{~K} 9$ status would be reasonable. We tried to assess the methylation status of $\mathrm{H} 3 \mathrm{~K} 9$ by immunohistochemistry. However, the H3K9me2 immunohistochemical study has some shortcomings in assessing adipogenesis. First, H3K9me2 immunohistochemical positivity may represent the presence of $\mathrm{H} 3 \mathrm{~K} 9 \mathrm{me} 2$, but negativity may not represent demethylation of $\mathrm{H} 3 \mathrm{~K} 9 \mathrm{me} 2$ and negative staining may be found in $\mathrm{H} 3 \mathrm{~K} 9 \mathrm{me} 1$ or $\mathrm{H} 3 \mathrm{~K} 9 \mathrm{me} 3$. Second, H3K9me2 immunostaining shows the global genomic H3K9 methylation status without representing the H3K9 methylation status of specific PHF2 and C/EBP $\alpha$ target regions. For these reasons, we assessed the cytoplasm to evaluate adipogenesis. As mentioned in the materials and methods section, cytoplasmic features were categorized as clear to light granular, deeply granular or eosinophilic, and high grade features (rhabdoid, sarcomatoid, and unclassifiable high grade morphology). Cases with different features were categorized as higher cytoplasmic features. Those cytoplasmic features were correlated with the nuclear expression of PHF2 and $\mathrm{C} / \mathrm{EBP} \alpha$ in consideration of the role of these proteins in adipogenesis (Table 1). Those results were consistent with previous reports that an eosinophilic cytoplasm is associated with high-grade tumours, necrosis or haemorrhage [4].

Molecular characteristics of ccRCC have been identified [7]. In TCGA data for ccRCC, genetic alterations in $\mathrm{PHF} 2$ and $\mathrm{C} / \mathrm{EBP} \alpha$ were found in a single patient case $(0.2 \%)$ for each $[7,27,28]$. The patients had a PHF2 missense mutation and CEBPA truncating mutation, respectively. Copy number alterations were not identified in either gene. The mRNA expression of PHF2 was upregulated in 11 patients $(2.3 \%)$ and down-regulated in 28
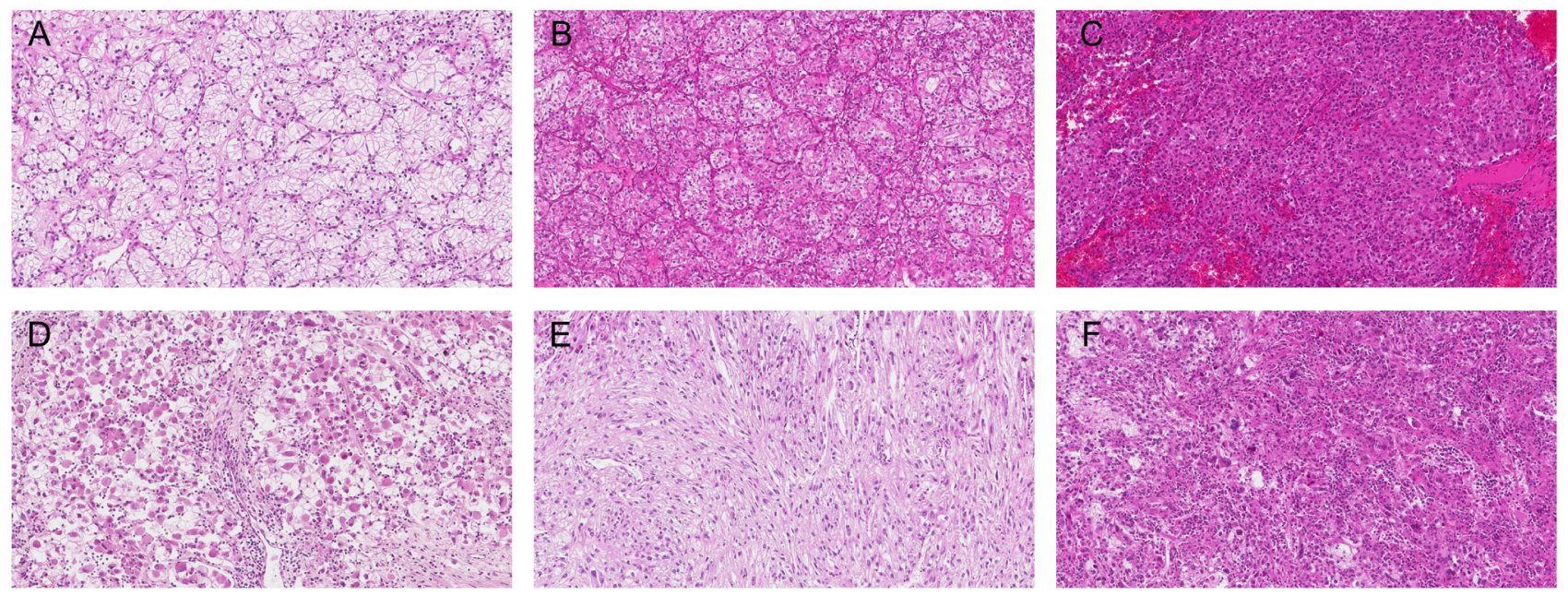

Figure 4: Cytoplasmic features of ccRCC based on adipogenesis. A. Clear to light granular, B.-C. deeply granular or eosinophilic, and D.-F. high grade features (rhabdoid D., sarcomatoid E., and unclassifiable high grade morphology F.). Original magnification, $\times 100$. 
patients $(6.0 \%)$, and the CEBPA mRNA expression was up-regulated in 22 patients $(4.7 \%)$, while down-regulation was not identified. Alterations in the protein expression were not identified. Those results showed that both the PHF2 and CEBPA genes are mutated in a very small proportion of ccRCC patients and the mRNA expression of both genes was not constant. The TCGA datasets are not well correlated with our data; we observed low nuclear expression of PHF2 and $\mathrm{C} / \mathrm{EBP} \alpha$ in 187 patients (54.4\%). These discrepancies can be explained by considering that epigenetic regulation affects PHF2 and $\mathrm{C} / \mathrm{EBP} \alpha$ expression for a low frequency of both gene mutations and mRNA expression is not well correlated with the protein expression or nuclear location of proteins or the protein function for different mRNA levels. Those possibilities should be assessed in integrative genomic levels in a comprehensive manner that considers transcriptional and translational modifications.

Cancer cell metabolism has been at the forefront of cancer research, and metabolic changes in cancer cell have been widely studied [29-31]. Cancer cells require energy production and biosynthesis of macromolecules, including nucleotides, lipids and proteins. As $V H L$ mutation is the most common genetic alteration in ccRCC and VHL affects cellular energy metabolism through HIF$1 \alpha$, ccRCC cases have received substantial attention at the metabolic level [7, 32, 33]. A cancer metabolic study by NGS for DNA sequencing or transcriptome analysis revealed that a worse prognosis in ccRCC was correlated with up-regulation of fatty acid synthesis genes [7]. This includes increased acetyl-CoA carboxylase (ACC) protein and fatty acid synthase (FASN) mRNA levels. Metabolites analysis in ccRCC showed increased metabolite levels in fatty acid biosynthesis during tumourigenesis and reversal of this pattern during progression [33]. Additionally, the study revealed that medium chain fatty acids are decreased in late-stage tumours, which is consistent with the observation that the lipid content is decreased in highgrade ccRCC [34]. The results of mRNA sequencing and metabolite analysis were not well correlated in our study or in other studies. The previous studies assessed ADFP and our results suggested that adipogenesis is associated with tumour initiation and decreased adipogenic function of $\mathrm{ADFP}$ and $\mathrm{PHF} 2$ and $\mathrm{C} / \mathrm{EBP} \alpha$ with tumour progression $[9,10]$. The discrepancy between decreased ADFP, PHF2 and $\mathrm{C} / \mathrm{EBP} \alpha$ expression and increased fatty acid synthesis genes in advanced ccRCC can be explained in several ways. First, ADFP, PHF2 and $\mathrm{C} / \mathrm{EBP} \alpha$ are regulatory proteins that are associated with adipogenesis, and they do not individually correlate with enzymes in fatty acid synthesis. Second, the enzyme levels, ACC and FASN levels can be affected by various molecules and conditions. Third, increased fatty acid synthesis genes do not indicate there is increased adipogenesis and may be a result of the negative feedback of products. Indeed, as mentioned before, medium chain fatty acids are decreased in advanced ccRCC in metabolite analysis [33]. These raised the possibility of another adipogenic pathway in ccRCC metabolism. Additionally, transcriptome analysis showed that poor survival is correlated with decreased Krebs cycle activity (tricarboxylic acid cycle, TCA cycle) [7]. Metabolite analysis revealed that glucose, citrate and glutamate are increased in ccRCC cancer cells compared to normal tissue and there is a decreased citrate level in high stage ccRCC compared to low stage ccRCC [33]. Based on another possible adipogenic pathway, increased glutamate in cancer and a decreased citrate level in highstage ccRCC led us to consider adipogenic metabolic evolution. We suggested sequential evolution based on adipogenesis in ccRCC (Figure 3). In our hypothetical adipogenic metabolic evolution, ccRCC cancer cells undergoing tumourigenesis are in a sufficient energy state due to the VHL/HIF pathway. Additionally, fertile energy leads to physiologic adipogenesis with ADFP, $\mathrm{PHF} 2$ and $\mathrm{C} / \mathrm{EBP} \alpha$ overexpression. This status can be called an oncogenic metabolic shift. As tumour progresses, glutamine-dependent lipogenesis is dominant and previous physiologic adipogenesis is decreased. Advanced cancer does not reach the energy requirement, which would further affect metabolic alterations. Additionally, the precise regulation of metabolism would be disrupted due to the accumulation of genetic alterations. Additionally, because PHF2 and $\mathrm{C} / \mathrm{EBP} \alpha$ are considered to have a tumour suppressive effect, subclones of cancer that suppress PHF2 and $\mathrm{C} / \mathrm{EBP} \alpha$ would have a survival advantage in tumour progression. As adipogenic metabolism is switched from the physiologic pathway to a Warburg-like effect, cancer cells become more pleomorphic and aggressive and have a non-clear morphology. Additionally, we named this status 'oncogenic metabolic progression' when considering the specific condition of ccRCC and difference from the oncogenic metabolic shift. Our hypothesis can explain our results and previous studies; however, more detailed evaluation and studies are needed for confirmation.

In summary, we evaluated the clinicopathologic correlation and prognostic significance of nuclear $\mathrm{PHF} 2$ and $\mathrm{C} / \mathrm{EBP} \alpha$ expression in ccRCC using an immunohistochemical study. We demonstrated that a low expression level of PHF2 and $\mathrm{C} / \mathrm{EBP} \alpha$ was significantly correlated with a larger tumour size, higher WHO/ISUP grade, high pM stage, advanced pTNM stage, and shorter overall, cancer-specific and progression-free survival times. Multivariate analysis showed that PHF2 expression and $\mathrm{C} / \mathrm{EBP} \alpha$ expression are independent prognostic factors for cancer-specific and progression-free survival and could act as novel prognostic markers in ccRCC patients. Furthermore, cytoplasmic features were associated with the PHF2 and $\mathrm{C} / \mathrm{EBP} \alpha$ expression and patient prognosis. Based on the adipogenic role of PHF2 and $\mathrm{C} / \mathrm{EBP} \alpha$, we suggested adipogenic metabolic evolution and our consideration may elucidate a therapeutic strategy for cancer cell metabolism. 


\section{MATERIALS AND METHODS}

\section{Patients and clinicopathologic information}

A total of 344 patients ( 251 men, 93 women) with ccRCC who underwent radical or partial nephrectomy between January 1, 2005, and March 31, 2008, at Seoul National University Hospital were included in this retrospective study. Each ccRCC sample was evaluated according to the RCC histologic type, WHO/ISUP grade and tumour stage. WHO/ISUP grades were reviewed based on the description in Delahunt et al. [35]. Tumour staging was re-assessed according to the 2010 TNM classification system [6] by reviewing the gross description, gross photos and representative slides. Tumour recurrence or distant metastasis of ccRCC was determined according to the clinical and radiologic findings. Disease-related deaths were verified by reviewing the patients' medical records. This study was approved by the Institutional Review Board of Seoul National University Hospital (IRB No. 1609-020-789).

\section{Tissue microarray (TMA)}

The haematoxylin and eosin ( $\mathrm{H} \& \mathrm{E}$ stain) slides from 344 ccRCC patients were reviewed. For TMA construction, a sufficient viable tumour portion with no haemorrhage or necrosis was selected in each case. Two representative core sections ( $2 \mathrm{~mm}$ in diameter), one for dominant histologic features and the other for high grade areas, were taken from formalin-fixed paraffin blocks because of the tumour heterogeneity. They were embedded in new recipient paraffin blocks (TMA blocks) using a trephine apparatus (Superbiochips Laboratories, Seoul, Korea). Additionally, cortical and medullary portions of 15 non-neoplastic kidney tissues from ccRCC patients were included as a control group.

\section{Evaluation of the cytoplasmic features of ccRCC}

H \& E staining was performed on $4 \mu$ m-thick sections taken from the TMA blocks. Cytoplasmic features based on adipogenesis were evaluated in 3 categories. We first categorized as clear cytoplasm versus non-clear cytoplasm. Further, we classified non-clear group into non-clear cytoplasm with low WHO/ISUP grade versus non-clear cytoplasm with high grade features (rhabdoid, sarcomatoid, and unclassifiable high grade morphology). Finally, we grouped into clear to light granular, deeply granular or eosinophilic, and high grade features (Figure 4). Each core was evaluated and cases with different cytoplasmic features were categorized into a higher grade category (Supplementary Figure 1).

\section{Immunohistochemistry of PHF2 and C/EBP $\alpha$}

The immunohistochemical staining of PHF2 and $\mathrm{C} / \mathrm{EBP} \alpha$ was conducted on $4-\mu \mathrm{m}$ thick sections collected from the TMA slides. TMA slides were treated to remove wax and rehydrated in a graded series of alcohol solutions. Immunohistochemical staining was performed using the Ventana BenchMark XT (Ventana Medical Systems, Tucson, AZ). Each polyclonal rabbit anti-PHF2 antibody (Novus Biologicals, Littleton, $\mathrm{CO}$ ) and polyclonal rabbit anti-C/EBP $\alpha$ antibody (Santa Cruz Biotechnology, Dallas, TX) was diluted 1:200. After the heat-induced antigen retrieval, the primary antibody was incubated with the samples for 15 minutes. The binding of the primary antibody was identified using the OptiView DAB IHC Detection Kit (Ventana Medical Systems) according to the manufacturer's instructions.

\section{Interpretation of TMA immunohistochemistry}

The nuclear staining of PHF2 and $\mathrm{C} / \mathrm{EBP} \alpha$ was assessed based on epigenetic regulation of adipogenesis of both antibodies. Immunoreactivity was semi-quantitatively evaluated by assessing the intensity and extent of nuclear staining. The intensity of immunostaining was sorted into negative, weak, moderate, and strong. The extent of immunostaining was divided into $0 \%$, less than or equal to $10 \%$, greater than 10 to less than or equal to $50 \%$, and greater than $50 \%$. Collectively, immunoreactivity with moderate to strong intensity an extent of greater than $10 \%$ is classified as positive staining and immunoreactivity with weak staining with any extent and moderate to strong intensity an extent of less than $10 \%$ negative staining. The cutoff value $10 \%$ showed the most reliable results. For each antibody, cases that were negative in both cores were designated as having low expression and cases that were positive in at least one core were classified as having high expression. Finally, cases with low expression in PHF2 and/or $\mathrm{C} / \mathrm{EBP} \alpha$ were classified as the low expression group, whereas cases with high expression in both PHF2 and $\mathrm{C} / \mathrm{EBP} \alpha$ were classified as the high expression group (Supplementary Figure 2).

\section{Statistical analysis}

The relationship between the nuclear expression of PHF2 and C/EBP $\alpha$ and adipogenesis was analysed with the Pearson's $\chi^{2}$ test. Correlations between their expression level and clinicopathological parameters were analysed by the Pearson's $\chi^{2}$ and Fisher exact tests. The progressionfree survival period was determined as the interval 
between the primary radical or partial nephrectomy and the final follow-up visit or identification of recurrence or metastasis of the ccRCC. The cancer-specific survival period was defined by the interval between the primary radical or partial nephrectomy and the final follow-up visit or cancer-related death. For survival analyses, the Kaplan-Meier curve and log-rank test were applied, and the univariate analysis of overall, cancer-specific, or progression-free survival was performed. A Cox proportional hazard model was applied for the multivariate analysis. In all statistical analyses, a two-tailed $P<0.05$ was considered statistically significant. All statistical analyses were performed using IBM SPSS Statistics 21 (IBM SPSS Inc., Chicago, IL, USA).

\section{Abbreviations}

ADFP, adipose differentiation-related protein; AML, acute myeloid leukaemia; ccRCC, clear cell renal cell carcinoma; $\mathrm{C} / \mathrm{EBP} \alpha, \mathrm{CCATT} /$ enhancer binding protein $\alpha$; $F A S N$, fatty acid synthase; HIF, hypoxia inducible factor; NGS, next-generation sequencing; $P B R M 1$, polybromo-1; PHF2, Plant homeodomain finger 2; RCC, renal cell carcinoma; VHL, Von Hippel-Lindau

\section{CONFLICTS OF INTEREST}

The authors declare that they have no conflict of interest.

\section{FUNDING}

This work was supported by grant 04-2014-0310 from the Seoul National University Hospital Research Fund.

\section{Editorial note}

This paper has been accepted based in part on peerreview conducted by another journal and the authors' response and revisions as well as expedited peer-review in Oncotarget.

\section{REFERENCES}

1. Hsieh JJ, Purdue MP, Signoretti S, Swanton C, Albiges L, Schmidinger M, Heng DY, Larkin J, Ficarra V. Renal cell carcinoma. Nat Rev Dis Primers. 2017; 3:17010.

2. Choueiri TK, Motzer RJ. Systemic Therapy for Metastatic Renal-Cell Carcinoma. N Engl J Med. 2017; 376:354-366.

3. Dabestani S, Thorstenson A, Lindblad P, Harmenberg U, Ljungberg B, Lundstam S. Renal cell carcinoma recurrences and metastases in primary non-metastatic patients: a population-based study. World J Urol. 2016; 34:1081-1086.

4. Moch H, Bonsib SM, Delahunt B, Eble J, Egevad L, Grignon DJ, Linehan WM, Reuter VE, Srigley JR, Sulser T, Tan PH. Clear cell renal cell carcinoma. In: Moch H, Humphrey PA, Ulbright TM, Reuter VE. World Health Organization Classification of Tumours of the Urinary System and Male Genital Organs. 4th ed. Lyon: IARC Press. 2016. p. 18-21.

5. Hoffmann NE, Gillett MD, Cheville JC, Lohse CM, Leibovich BC, Blute ML. Differences in organ system of distant metastasis by renal cell carcinoma subtype. J Urol. 2008; 179:474-477.

6. Edge SB, Byrd DR, Compton CC, Fritz AG, Greene FL, Trotti A. Kidney. In: Edge SB, Byrd DR, Compton CC, Fritz AG, Greene FL, Trotti A. AJCC Cancer Staging Manual. 7th ed. New York: Springer. 2009. p. 479-489.

7. Cancer Genome Atlas Research N. Comprehensive molecular characterization of clear cell renal cell carcinoma. Nature. 2013; 499:43-49.

8. Varela I, Tarpey P, Raine K, Huang D, Ong CK, Stephens P, Davies H, Jones D, Lin ML, Teague J, Bignell G, Butler A, Cho J, et al. Exome sequencing identifies frequent mutation of the SWI/SNF complex gene PBRM1 in renal carcinoma. Nature. 2011; 469:539-542.

9. Yao M, Tabuchi H, Nagashima Y, Baba M, Nakaigawa N, Ishiguro H, Hamada K, Inayama Y, Kishida T, Hattori K, Yamada-Okabe H, Kubota Y. Gene expression analysis of renal carcinoma: adipose differentiation-related protein as a potential diagnostic and prognostic biomarker for clear-cell renal carcinoma. J Pathol. 2005; 205:377-387.

10. Tun HW, Marlow LA, von Roemeling CA, Cooper SJ, Kreinest P, Wu K, Luxon BA, Sinha M, Anastasiadis PZ, Copland JA. Pathway signature and cellular differentiation in clear cell renal cell carcinoma. PLoS One. 2010; 5:e10696.

11. Okuno Y, Ohtake F, Igarashi K, Kanno J, Matsumoto T, Takada I, Kato S, Imai Y. Epigenetic regulation of adipogenesis by PHF2 histone demethylase. Diabetes. 2013; 62:1426-1434.

12. Okuno Y, Inoue K, Imai Y. Novel insights into histone modifiers in adipogenesis. Adipocyte. 2013; 2:285-288.

13. Lee KH, Ju UI, Song JY, Chun YS. The histone demethylase PHF2 promotes fat cell differentiation as an epigenetic activator of both C/EBPalpha and C/EBPdelta. Mol Cells. 2014; 37:734-741.

14. Sinha S, Singh RK, Alam N, Roy A, Roychoudhury $\mathrm{S}$, Panda CK. Alterations in candidate genes PHF2, FANCC, PTCH1 and XPA at chromosomal 9q22.3 region: pathological significance in early- and late-onset breast carcinoma. Mol Cancer. 2008; 7:84.

15. Sun LL, Sun XX, Xu XE, Zhu MX, Wu ZY, Shen JH, Wu JY, Huang Q, Li EM, Xu LY. Overexpression of Jumonji AT-rich interactive domain $1 \mathrm{~B}$ and PHD finger protein 2 is 
involved in the progression of esophageal squamous cell carcinoma. Acta Histochem. 2013; 115:56-62.

16. Lee KH, Park JW, Sung HS, Choi YJ, Kim WH, Lee HS, Chung HJ, Shin HW, Cho CH, Kim TY, Li SH, Youn HD, Kim SJ, et al. PHF2 histone demethylase acts as a tumor suppressor in association with p53 in cancer. Oncogene. 2015; 34:2897-2909.

17. Tenen DG. Abnormalities of the CEBP alpha transcription factor: a major target in acute myeloid leukemia. Leukemia. 2001; 15:688-689.

18. Schuster MB, Porse BT. C/EBPalpha: a tumour suppressor in multiple tissues? Biochim Biophys Acta. 2006; 1766:88103.

19. Konopka B, Szafron LM, Kwiatkowska E, Podgorska A, Zolocinska A, Pienkowska-Grela B, DansonkaMieszkowska A, Balcerak A, Lukasik M, Stachurska A, Timorek A, Spiewankiewicz B, El-Bahrawy M, et al. The significance of c.690G $>$ T polymorphism (rs34529039) and expression of the CEBPA gene in ovarian cancer outcome. Oncotarget. 2016; 7:67412-67424. https://doi.org/10.18632/ oncotarget.11822.

20. Seipel K, Marques MT, Bozzini MA, Meinken C, Mueller BU, Pabst T. Inactivation of the p53-KLF4-CEBPA Axis in Acute Myeloid Leukemia. Clin Cancer Res. 2016; 22:746756.

21. Young AN, Amin MB, Moreno CS, Lim SD, Cohen C, Petros JA, Marshall FF, Neish AS. Expression profiling of renal epithelial neoplasms: a method for tumor classification and discovery of diagnostic molecular markers. Am J Pathol. 2001; 158:1639-1651.

22. Halmos B, Huettner CS, Kocher O, Ferenczi K, Karp DD, Tenen DG. Down-regulation and antiproliferative role of C/ EBPalpha in lung cancer. Cancer Res. 2002; 62:528-534.

23. Gery S, Tanosaki S, Bose S, Bose N, Vadgama J, Koeffler HP. Down-regulation and growth inhibitory role of $\mathrm{C} /$ EBPalpha in breast cancer. Clin Cancer Res. 2005; 11:31843190.

24. Shim M, Powers KL, Ewing SJ, Zhu S, Smart RC. Diminished expression of C/EBPalpha in skin carcinomas is linked to oncogenic Ras and reexpression of C/EBPalpha in carcinoma cells inhibits proliferation. Cancer Res. 2005; 65:861-867.

25. Timchenko NA, Harris TE, Wilde M, Bilyeu TA, BurgessBeusse BL, Finegold MJ, Darlington GJ. CCAAT/enhancer binding protein alpha regulates 21 protein and hepatocyte proliferation in newborn mice. Mol Cell Biol. 1997; 17:7353-7361.
26. Harris TE, Albrecht JH, Nakanishi M, Darlington GJ. CCAAT/enhancer-binding protein-alpha cooperates with p21 to inhibit cyclin-dependent kinase-2 activity and induces growth arrest independent of DNA binding. J Biol Chem. 2001; 276:29200-29209.

27. Gao J, Aksoy BA, Dogrusoz U, Dresdner G, Gross B, Sumer SO, Sun Y, Jacobsen A, Sinha R, Larsson E, Cerami E, Sander C, Schultz N. Integrative analysis of complex cancer genomics and clinical profiles using the cBioPortal. Sci Signal. 2013; 6:pl1.

28. Cerami E, Gao J, Dogrusoz U, Dresdner G, Gross B, Sumer SO, Sun Y, Jacobsen A, Sinha R, Larsson E, Cerami E, Sander C, Schultz N. The cBio cancer genomics portal: an open platform for exploring multidimensional cancer genomics data. Cancer Discov. 2012; 2:401-404.

29. Warburg O. On the origin of cancer cells. Science. 1956; 123:309-314.

30. Vander Heiden MG, Cantley LC, Thompson CB. Understanding the Warburg effect: the metabolic requirements of cell proliferation. Science. 2009; 324:10291033.

31. Cantor JR, Sabatini DM. Cancer cell metabolism: one hallmark, many faces. Cancer Discov. 2012; 2:881-898.

32. Linehan WM, Srinivasan R, Schmidt LS. The genetic basis of kidney cancer: a metabolic disease. Nat Rev Urol. 2010; 7:277-285.

33. Hakimi AA, Reznik E, Lee $\mathrm{CH}$, Creighton CJ, Brannon AR, Luna A, Aksoy BA, Liu EM, Shen R, Lee W, Chen Y, Stirdivant SM, Russo P, et al. An Integrated Metabolic Atlas of Clear Cell Renal Cell Carcinoma. Cancer Cell. 2016; 29:104-116.

34. Gebhard RL, Clayman RV, Prigge WF, Figenshau R, Staley NA, Reesey C, Bear A. Abnormal cholesterol metabolism in renal clear cell carcinoma. J Lipid Res. 1987; 28:11771184.

35. Delahunt B, Cheville JC, Martignoni G, Humphrey PA, Magi-Galluzzi C, McKenney J, Egevad L, Algaba F, Moch H, Grignon DJ, Montironi R, Srigley JR. The International Society of Urological Pathology (ISUP) grading system for renal cell carcinoma and other prognostic parameters. Am J Surg Pathol. 2013; 37:1490-1504. 